\title{
Mutational Analysis of Amino Acid Positions Crucial for IgE-Binding Epitopes of the Major Apple (Malus domestica) Allergen, Mal d 1
}

\author{
Yan Ma $^{\mathrm{a}}$ Gabriele Gadermaier $^{\mathrm{b}}$ Barbara Bohle ${ }^{\mathrm{a}}$ Suzanne Bolhaar ${ }^{\mathrm{c}}$ \\ Andre Knulst ${ }^{c}$ Zora Markovic-Housley $^{d}$ Heimo Breiteneder $^{a}$ Peter Briza $^{b}$ \\ Karin Hoffmann-Sommergruber ${ }^{a}$ Fatima Ferreira $^{b}$ \\ ${ }^{a}$ Department of Pathophysiology, Medical University of Vienna, Vienna, ${ }^{b}$ Department of Molecular Biology, \\ University of Salzburg, Salzburg, Austria; ' Department of Dermatology/Allergology, University Medical Center

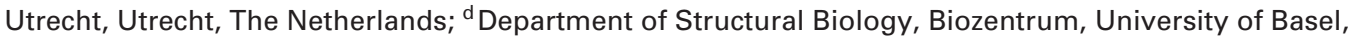 \\ Basel, Switzerland
}

\section{Key Words}

Mal d $1 \cdot$ Bet v $1 \cdot$ Apple allergy · Hypoallergenic $\cdot$

Recombinant allergen · Point mutation

\begin{abstract}
Background: Individual amino acid residues of the major birch pollen allergen, Bet $v 1$, have been identified to be crucial for IgE recognition. The objective of the present study was to evaluate whether this concept was applicable for the Bet $v$ 1-homologous apple allergen, Mal d 1. Methods: A Mal d 1 five-point mutant was produced by PCR techniques, cloned into pMW 172 and expressed in Escherichia coli BL21(DE3) cells. To evaluate the allergenic properties of the engineered protein compared to Mal d 1 wild-type lgE immunoblotting, ELISA, peripheral blood monocytes proliferation assays, and skin prick tests were performed. Results: The Mal d 1 mutant showed reduced capacity to bind specific IgE as compared to wild-ype Mal d 1 in in vitro assays in the majority of the sera tested. In ELISA, 10 out of 14 serum samples displayed an 88-30\% decrease in IgE binding to Mal d 1 mutant compared to wild-type Mal d 1. Skin prick
\end{abstract}

Y.M. and G.G. contributed equally.

\section{KARGER}

Fax +4161306 1234 E-Mail karger@karger.ch www.karger.com (c) 2006 S. Karger AG, Basel $1018-2438 / 06 / 1391-0053 \$ 23.50 / 0$

Accessible online at: www.karger.com/iaa tests in apple-allergic patients $(n=2)$ confirmed the markedly decreased ability of the Mal d 1 mutant to induce allergic reactions in vivo. However, the relevant $T$ cell epitopes were present in the mutated molecule according to peripheral blood mononuclear cell proliferation assays. Conclusions: Our findings suggest that it is possible to modulate the lgE-binding properties of allergens by single amino acid substitutions at crucial positions which might be useful for future immunotherapy of birch-pollen-associated food allergies which are not ameliorated by birch pollen immunotherapy.

Copyright (C) 2006 S. Karger AG, Basel

\section{Introduction}

Patients suffering from allergy to birch pollen often develop allergic reactions after ingestion of various fruits (e.g. apple, pear, peach, cherry), nuts (e.g. hazelnut, walnut), and vegetables (e.g. celery, carrot, potato) [1-3]. The major birch pollen allergen, Bet $\mathrm{v} 1$, and its corresponding homologues in these foods could be identified as the cross-reactive molecules mainly responsible for this form of food allergy [4-8]. The deduced amino acid sequence of Mal d 1, the major apple allergen, shows 55\% identity to Bet v 1a (EMBL, Genbank Database access No.

Correspondence to: Dr. Karin Hoffmann-Sommergruber

Department of Pathophysiology, Medical University Vienna AKH-EBO 3Q

Währinger Gürtel 18-20, AT-1090 Vienna (Austria)

Tel. +431 404005132 , Fax +43140400 5130

E-Mail Karin.Hoffmann-Sommergruber@meduniwien.ac.at 
X15877; [7, 9]). Cross-inhibition experiments demonstrated that recombinant Mal d 1 shares IgE epitopes with Bet v 1a [7]. In addition, Mal d 1 also shares T cell epitopes with the major birch pollen allergen, Bet v 1 [10]. This homology is also reflected by the clinical observation that apple allergy starts after the onset of birch pollinosis $[4,10-12]$. The hypothesis suggests that Bet $\mathrm{v} 1$ sensitization initiates allergic reactions to Mal d 1 .

Therefore, one would assume that successful birch pollen specific immunotherapy (SIT) should also ameliorate the symptoms of concomitant apple allergy. However, this issue is still controversial, and studies supporting as well as contradicting this hypothesis were published [1315].

Previously, we proposed a new concept for the development of vaccines for SIT. Using site-directed mutagenesis, allergen variants were engineered that display significantly reduced allergenicity in terms of IgE binding and thus reducing the risk of developing anaphylactic reactions upon injection. On the other hand, these allergen mutants are still recognized by $\mathrm{T}$ helper cells and can therefore modulate the allergic immune response at the $\mathrm{T}$ cell level, a characteristic shown to be essential for successful immunotherapy [16-18].

Our approach was validated using the Bet v 1 molecule and introducing six-point mutations at critical positions. The resulting molecule was still recognized by allergenspecific $\mathrm{T}$ lymphocytes, but displayed significantly reduced IgE binding capacity, as determined by in vivo and in vitro tests [19].

In the present study we investigated whether the amino acid residues/positions shown to be involved in the formation of IgE-binding epitopes of Bet $\mathrm{v} 1$ are also crucial for IgE recognition of Mal d 1, the homologous allergen from apple. This was tested using a PCR-based sitedirected mutagenesis approach to produce a Mal d $1 \mathrm{mu}-$ tant protein and to evaluate whether it would represent a candidate for SIT in pollen-related apple allergy.

\section{Materials and Methods}

\section{DNA Constructs}

The cDNA coding for Mal d 1.0108 (EMBL Genbank Database access No. AJ417551) was cloned into the pMW172 expression vector [20] as previously described [7, 21]. The five-point Mal d 1 mutant was generated using the three-primer PCR mutagenesis method [19]: Thr10 $\rightarrow$ Pro; Ile 30 $\rightarrow$ Val; Thr57 $\rightarrow$ Asn; Thr112 $\rightarrow$ Cys; Ile113 $\rightarrow$ Val (fig. 1). One additional exchange shown to be important for IgE recognition of Bet v 1a (position 125, Asp $\rightarrow$ Asn) was not engineered in the Mal d 1 sequence as asparagine is already present in the original wild-type sequence.
The oligonucleotides were obtained from MWG Biotech AG (Ebersberg, Germany), restriction enzymes from MBI Fermentas $\mathrm{GmbH}$ (St. Leon-Rot, Germany) and all the other chemicals used were purchased from Sigma-Aldrich Chemie (Sleinheim, Germany).

\section{Internal Mutagenic Primers}

M30 5'-AATCTTGGGGAcGAGGTTGTC-3'; M57 5'-TTCACCAAAAtTGATCTTCTTG-3'; M112 + 113 5'-GTGGTTCCtgCgTCAAGAGCATC-3'. The exchanged bases are indicated in lower case. For mutation at position 10: M10: 5'-GGGCATATGGGTGTGTACACCTTCGAGAACGAGTTCcCCTCTG-3'; Flanking primers: Nde I (underlined) 5'-GGGCATATGGGTGTGTACACCTTCGAG-3' and EcoR I (underlined) 5'-CAAGGAATTCTTAGTTGTAGGCATCCGGGTGGTCCTT-3'.

The PCR products were digested with $N d e$ I and EcoR I and subcloned in expression vector pMW172. Competent Escherichia coli BL21 cells were transformed with the resulting plasmids.

In the following Mal d 1.0108 will be referred to as Mal d 1 wildtype (Mal d 1wt) and the engineered mutant thereof as Mal d 1 mutant (Mal d 1mut).

Expression and Preparation of E. coli Cell Lysates of Allergen Wild Types and Mutants

A single transformant colony of pMW172/Mal d 1wt and pMW172/Mal d 1mut, respectively, was picked and grown in $\mathrm{LB} / 100 \mathrm{mg} / \mathrm{l}$ ampicillin under constant shaking at $37^{\circ} \mathrm{C}$ to an $\mathrm{OD}_{600}$ of 1.0. Expression of recombinant proteins was induced and harvested as described previously [22].

Insoluble inclusion bodies containing rMal d $1 \mathrm{wt}$ and $\mathrm{rMal}$ d 1 mut were solubilized in buffer A (20 m M imidazole, pH 7.4/4\% isopropanol) containing $6 \mathrm{M}$ urea and dialyzed stepwise against buffer A with decreasing urea concentrations $(4 M, 2 M, 1 M$, $0.5 \mathrm{M}$ ) and final buffer A at $4^{\circ} \mathrm{C}$ (dialysis tubes - Spectra/Por Membrane with MWCO of 10,000, Medicell International Ltd, London, UK). Subsequently, the extracts were subjected to further purification by DEAE chromatography applying a $10 \times 100 \mathrm{~mm}$ column packed with DEAE-Sepharose Fast flow (Amersham, Biosciences, Little Chalfont, UK). A linear gradient was performed (buffer A: $20 \mathrm{~m} M$ imidazole $\mathrm{pH} 7.4 / 4 \%$ isopropanol; buffer B: buffer A/ $250 \mathrm{~m} M \mathrm{NaCl}$; gradient $0-100 \%$ ) within $100 \mathrm{ml}$. Afterwards, the proteins were purified by separation over a phenyl cellufine column $(10 \times 100 \mathrm{~mm}$; Biorad, Hercules, Calif., USA; buffer A: $0.8 \mathrm{M}$ $\mathrm{NaCl} / 15 \mathrm{~m} M \mathrm{NaH}_{2} \mathrm{PO}_{4} / 10 \mathrm{~m} M$ acetic acid $\mathrm{pH} 4.5$; gradient $0-$ 100\% B within $100 \mathrm{ml}$. Fractions were checked by SDS-PAGE analysis and the pure protein fractions pooled and lyophilized.

Purified recombinant Bet v 1a [EMBL, Genbank Database accession No. X15877, referred to here as Bet v 1 wild-type (Bet $\mathrm{v} 1 \mathrm{wt}$ )] and Bet $\mathrm{v} 1$ mutant (Bet $\mathrm{v} 1$ mut [19]) were purchased from Biomay (Vienna, Austria). All recombinant allergens were tested for bacterium-derived endotoxin levels using a limulus amoebocyte lysate assay according to the manufacturer's instructions (Bio Whittaker, Verviers, Belgium).

\section{Structural Models of Bet $v 1$ and Mald 1}

The 3D model of Mal d 1 was produced by Swiss Model software [23] using the structure of Bet $\mathrm{v} 1$ as a template (PDB code: 1BV1) and the sequence alignment of Bet v 1a and Mal d 1.0108 (fig. 1a). 


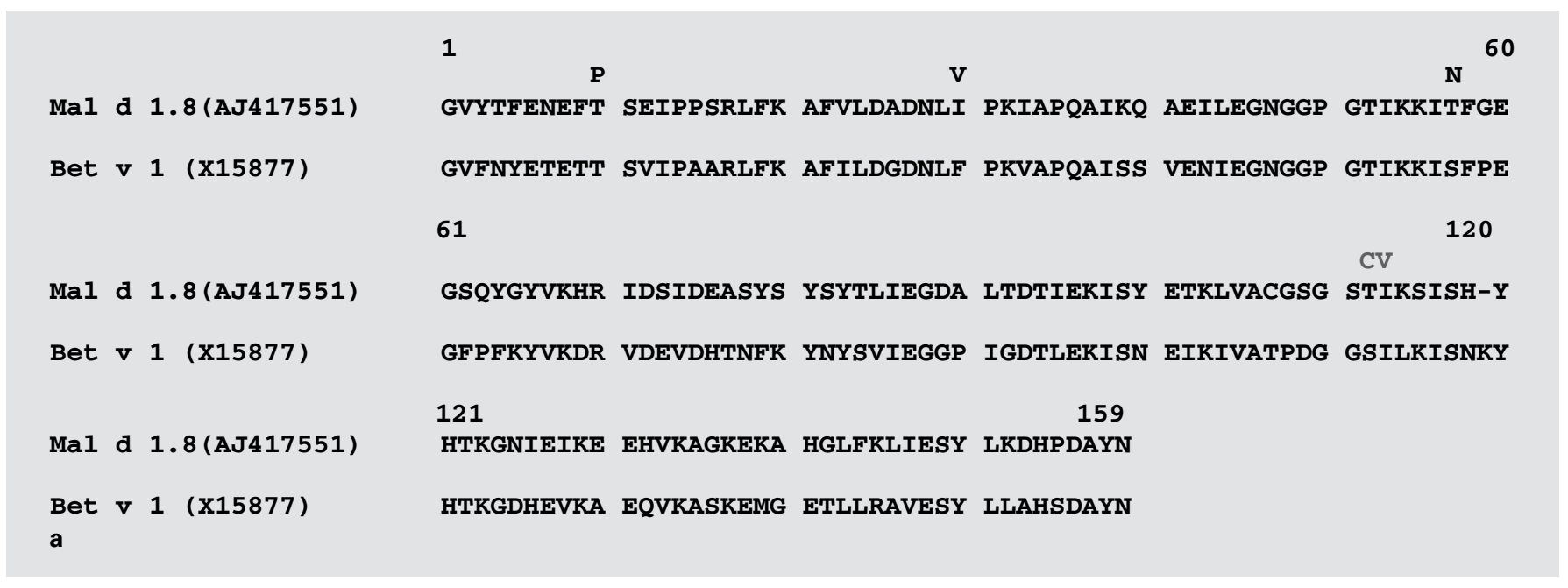

Fig. 1. a Sequence alignment of Mal d 1 and Bet v 1 (EMBL Genbank Database accession numbers are given in brackets). The introduced point mutations for Mal d 1 mut are indicated. b Ribbon diagram of the Bet $\mathrm{v} 1$ structure. The amino acids belonging to Mal d 1 mut are coloured red while the corresponding residues of Bet $\mathrm{v}$ 1wt and Mal d $1 \mathrm{wt}$ are coloured white and green, respectively.

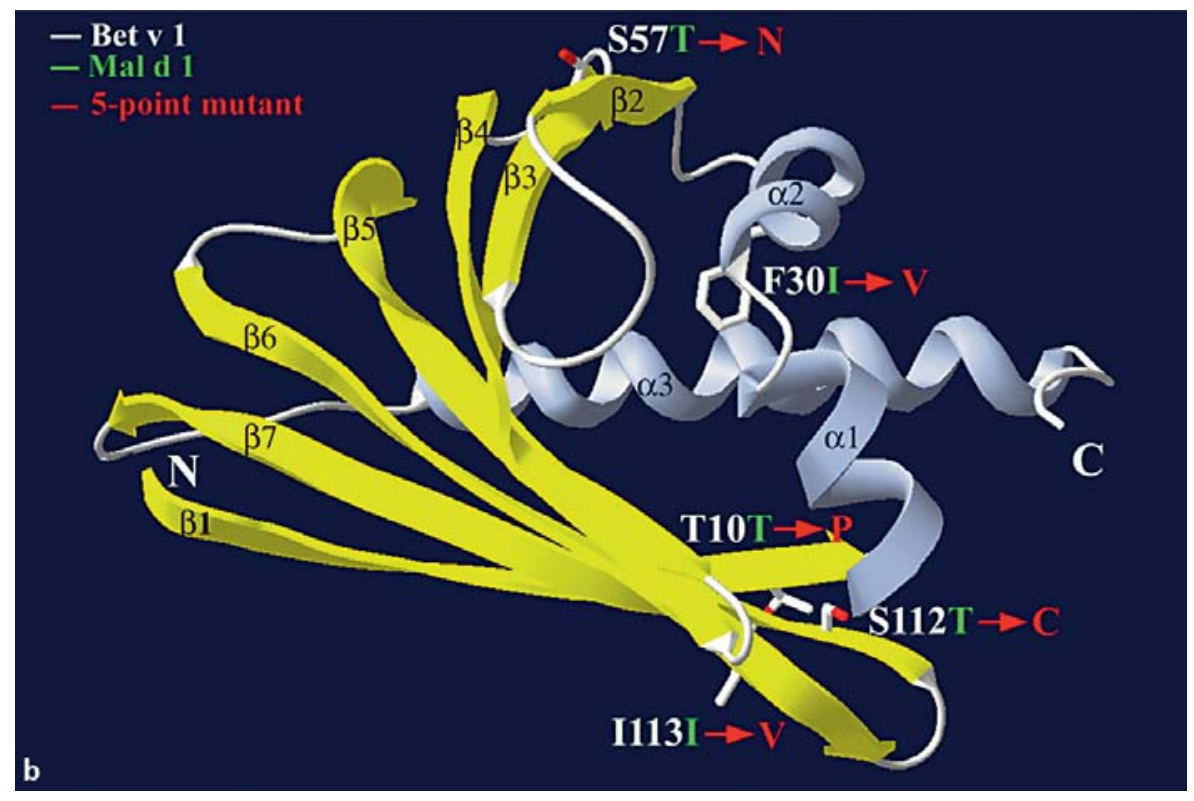

\section{$N$-Terminal Sequencing}

Fifty picomoles of purified rMal d 1wt and rMal d 1mut, respectively, were immobilized on polyvinylidene difluoride (PVDF) membranes (ProSorb sample preparation cartridges, Applied Biosystems, Foster City, Calif., USA) and analyzed as described [22].

Matrix-Assisted Laser Desorption/Ionization-Time of Flight

(MALDI-TOF) Mass Spectrometry

For determining intact molecular masses, purified rMal d 1wt and rMal d 1 mut were first reduced and alkylated. Briefly, samples were dried under vacuum and dissolved in $150 \mu 10.3 \mathrm{M}$ Tris- $\mathrm{HCl}$, pH 8.0, $8 M$ guanidinium-HCl, 1.3 $M$ EDTA. Dithiothreitol(DTT) was added in 50-fold molar excess and samples were incubated for $4 \mathrm{~h}$ at $50^{\circ} \mathrm{C}$. Afterwards, due to the cysteine residues present in the Mal d 1 sequences, $15 \mu \mathrm{mol}$ iodoacetamide was added and alkylation was performed for $1 \mathrm{~h}$ at $37^{\circ} \mathrm{C}$. The reaction was stopped by adding $7.5 \mu \mathrm{mol}$ of DTT. Samples were then extensively dialyzed against distilled water and vacuum dried.

For mass measurements, $0.5 \mu \mathrm{l}$ (approximately $0.5 \mu \mathrm{g}$ ) of reduced and alkylated rMal d 1wt and rMal d 1mut proteins were analyzed with the Kompact MALDI IV mass spectrometer (Kratos Analytical, Manchester, UK) in the linear flight mode as described previously [24].

\section{Circular Dichroism Spectra}

Circular dichroism (CD) measurements of purified rMal d 1wt and rMal d 1 mut $(0.15 \mu \mathrm{g} / \mu \mathrm{l})$ were performed in aqueous solutions using a Jasco J-810 spectropolarimeter (Japan Spectroscopic Co., Tokyo, Japan) fitted with an RTE-111M temperature control system (Nes-Lab) as described previously [25]. 
Patients and Sera

Within a study funded by the European Commission Framework 5, apple-allergic patients were selected in the Netherlands and Austria. Dutch patients were recruited at the Department of Dermatology/Allergology of University Medical Centre Utrecht and the Austrian patients at the Medical University of Vienna. All the patients reported immediate adverse reactions to apple ingestion and the inhalation of birch pollen together with a positive skin prick test (SPT) to fresh Golden Delicious apples. According to EAACI recommendations [26], SPT was considered positive if the wheal area was $7 \mathrm{~mm}^{2}$ (3 $\mathrm{mm}$ diameter) greater than the negative control. Furthermore, the sera selected for this study $(\mathrm{n}=30)$ displayed a positive RAST to apple $(>3.5 \mathrm{IU} / \mathrm{ml})$ as well as to Mal d 1 $(>1.8 \mathrm{IU} / \mathrm{ml})$. Sera from healthy donors $(\mathrm{n}=5)$ with negative case histories, negative SPT, and negative RAST were used as controls. The study was performed with the approval of the local ethics committees and with the patients' consent (or their legal representatives' consent).

\section{SDS-PAGE, IgE Immunoblots and ELISA}

Purified rMal d 1wt, rMal d 1mut, rBet v $1 \mathrm{wt}$, and rBet v 1 mut were subjected to $15 \%$ SDS-PAGE $(2 \mu \mathrm{g} /$ lane) [27] performed under reducing conditions and either visualized by Coomassie Brilliant Blue R-250 staining or further electroblotted onto nitrocellulose membranes [28]. The IgE-binding abilities of the purified recombinant proteins were detected applying sera from food-allergic patients (1:5 diluted in $50 \mathrm{mmol} / 1$ sodium phosphate buffer $/ 0.5 \%$ Tween 20/1\% BSA pH 7.5) according to established protocols [29]. Bound IgE was detected by ${ }^{125} \mathrm{I}$-labelled antihuman IgE antibodies (1:20 dilution; MALT Allergy System Isotope Reagent, IBL, Hamburg, Germany) and visualized by autoradiography. In parallel, the serum pool from 5 non-allergic subjects and buffer were used as controls.

For ELISA experiments the same set of proteins $(10 \mu \mathrm{g} / \mathrm{ml})$ was dissolved in $25 \mathrm{mM} \mathrm{NaHCO}$, pH 9.6 and coated on microtitre wells (Nunc Maxisorp, Nalge Nunc International, Roskilde, Denmark) overnight at $4^{\circ} \mathrm{C}$. Non-specific binding sites were blocked with $2 \%$ milk in TBS $/ 0.05 \%$ Tween $20(\mathrm{v} / \mathrm{v})$. Coated protein was incubated with sera from apple-allergic patients (1:5 dilution) overnight at $4^{\circ} \mathrm{C}$. Bound IgE from 14 apple allergic sera (No. 10-23) was detected with alkaline-phosphatase-conjugated mouse antihuman IgE antibody (1:1,000; BD-Biosciences Pharmingen, San Diego, Calif., USA) and developed with the $p$-nitrophenyl phosphate substrate. Colour development was measured using an ELISA reader (Spectra Max Plus 384; Molecular Devices GmbH, Munich, Germany) at $405 \mathrm{~nm}$ and $510 \mathrm{~nm}$ as reference wavelength. Optical density (OD) values from normal human serum $(n=5)$ samples were obtained and standard deviation calculated. All OD values from serum samples above mean value plus 3 standard deviations were considered positive.

\section{Titration SPT}

After obtaining written consent, SPT were performed in 2 apple-allergic patients on the flexor aspect of the forearm with fresh apple (Golden Delicious) and rMal d 1wt and rMal d 1 mut using a standardized prick needle (ALK-Lancet, Horsholm, Denmark [26, 30]). Allergen concentrations of 0.02, 0.2, 2, 20 and $100 \mu \mathrm{g} / \mathrm{ml}$ were applied and SPT reactivity was measured after 15 min by copying the wheal reaction with transparent adhesive tape onto a record sheet. Subsequently, the wheal area was determined by computer scanning [31]. Histamine dihydrochloride $(10 \mathrm{mg} / \mathrm{ml})$ was used as a positive control, and the glycerol containing diluents of the SPT extract was used as a negative control (ALK-Abelló, Nieuwegein, The Netherlands). SPT responses were standardized by dividing the original wheal area following a prick by that obtained for the histamine control; a relative wheal area of at least $0.25 \mathrm{SPT} /$ histamine, which is comparable to a reaction of $>1+$ by the standard procedure $[26,31]$, was considered positive.

\section{Proliferation Assays}

Peripheral blood mononuclear cells (PBMCs) were obtained from birch-pollen-allergic patients with oral allergy syndrome (OAS) to apples. Proliferative responses to three different concentrations of purified rMal d 1wt and rMal d 1 mut (doses: 6.3, 12.5 and $25 \mu \mathrm{g} / \mathrm{ml}$ ) were evaluated as described previously [32].

\section{Results}

\section{Sequence Analysis and Structural Modelling}

Recombinant Mal d 1wt and rMal d 1mut were produced according to established protocols. The five-point mutations for Mal d 1mut are marked in the sequence alignment (fig. 1a).

The 3D model of Mal d 1 was produced (Swiss Model software) by using the structure of Bet v 1.2801 (PDB code: 1BV1). The model of Mal d 1 (not shown) is almost identical to the Bet v 1 structure ( $\mathrm{rmsd}=1.9 \AA$ for 158 $\mathrm{C} \alpha$ atoms; fig. $1 \mathrm{~b}$ ) with significant differences occurring only in a loop joining the $\beta 7$ strand with C-terminal helix $\alpha 3$. Therefore, the structure of Bet $v 1$ is used in figure $1 b$ to show the location of the exchanged residues belonging to Mal d 1mut (fig. 1b).

\section{Expression, Purification, and Characterization of}

\section{rMal d 1wt and rMald 1mut}

Production in E. coli yielded $80 \mathrm{mg}$ purified recombinant Mal d 1wt and $40 \mathrm{mg}$ purified Mal d 1mut per litre culture, respectively. The proteins appeared as homogeneous single bands migrating at $17 \mathrm{kDa}$ as determined by SDS-PAGE and Coomassie staining (data not shown). $\mathrm{N}$-terminal analysis of both purified proteins revealed that the initiating methionine was cleaved off, resulting in the first five amino acid residues: GVYTF (data not shown) corroborating that the initiating methionine was cleaved off according to the side chain length of the penultimate amino acid [33].

The integrity of the primary structure was further verified by MALDI-TOF mass spectrometry analysis. The molecular weight of reduced and alkylated rMal d 1wt and rMal d 1mut proteins was measured as 17,556.65 (theoretical 17,549.72) and 17,576.87 (theo- 
Fig. 2. CD spectra of rMal d 1 wt (a) and rMal d 1 mut (b). Spectra were initially recorded at $25^{\circ} \mathrm{C}$ (continuous lines), and after heating to $95^{\circ} \mathrm{C}$ (dotted lines) followed by cooling to $25^{\circ} \mathrm{C}$ (dashed lines).

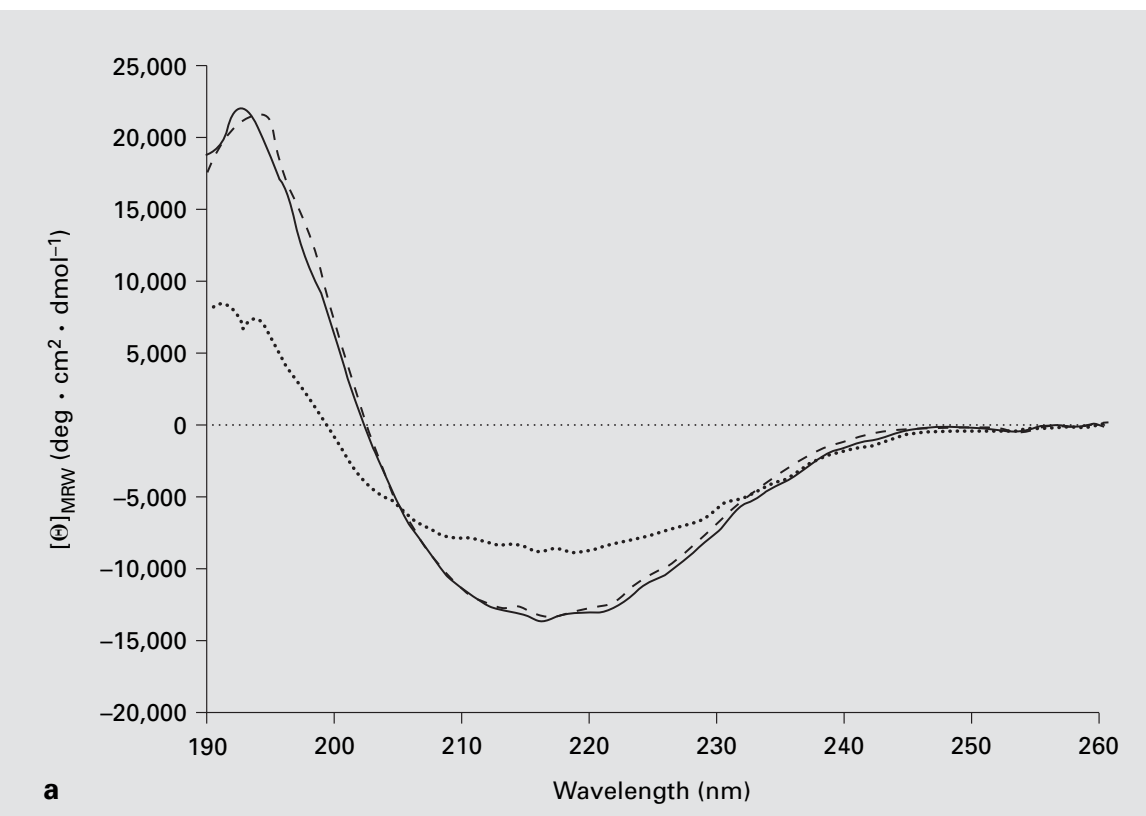

a

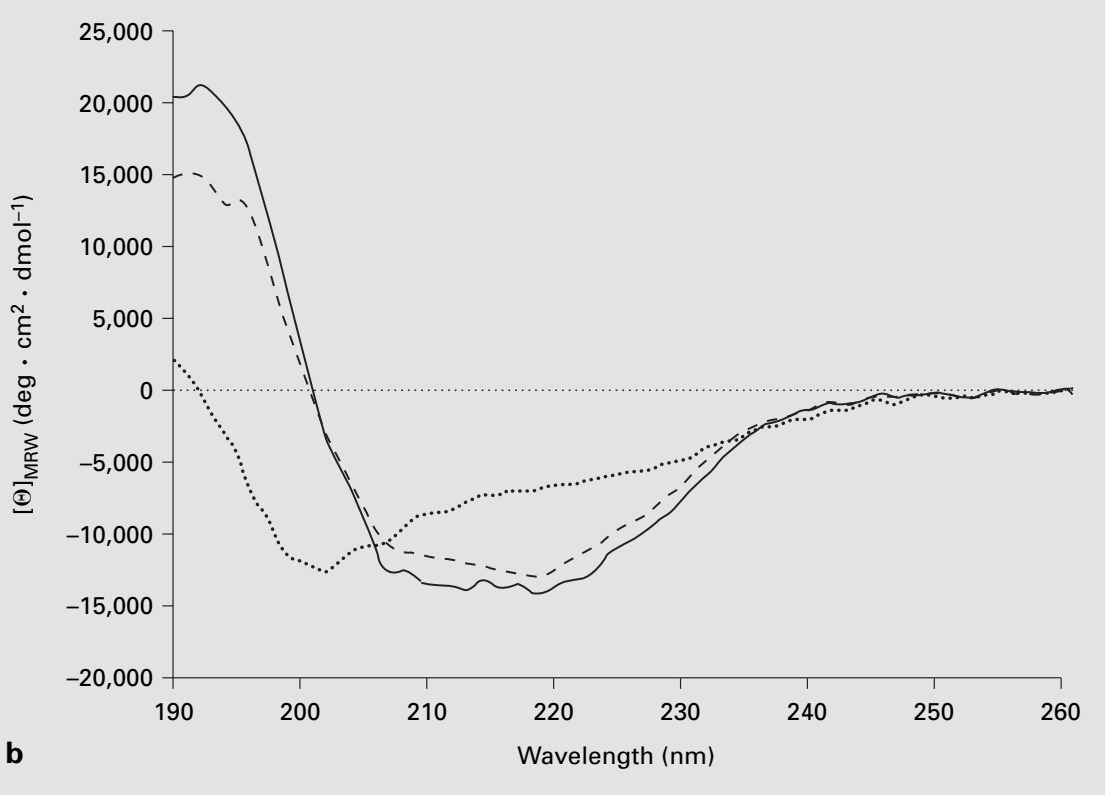

retical 17,589.76), respectively. Analysis for endotoxin levels yielded $0.23 \mathrm{EU} / \mu \mathrm{g}$ protein for purified rMal d $1 \mathrm{wt}$ and $0.08 \mathrm{EU} / \mu \mathrm{g}$ protein for $\mathrm{rMal} \mathrm{d} 1$ mut. These values are below the threshold values allowed for human therapeutics for parenteral application (e.g. Austrian threshold level: $8 \mathrm{EU} / \mathrm{ml}$ ).

CD spectra of rMal d 1wt and rMal d 1 mut showed that the preparations consisted of folded proteins and that the overall secondary structure content of the two proteins was very similar (fig. 2). On heating to $95^{\circ} \mathrm{C}$, the spectra of rMal d 1 mut changed to that of a random coil (fig. 2b), as usually observed with polypeptides undergoing thermal unfolding. However, rMal d 1 wt was not completely denatured after heating to $95^{\circ} \mathrm{C}$ (fig. 2a). Upon cooling to $25^{\circ} \mathrm{C}$, rMal d $1 \mathrm{wt}$ showed a CD spectrum similar in shape and peak amplitudes to the one recorded before heating, suggesting that rMal d 1wt is able to correctly refold after thermal denaturation. In contrast, thermally denatured rMal d 1 mut was only able to partially refold. 
Fig. 3. Immunoblot analysis of rMal d $1 \mathrm{wt}$ and rMal d 1mut, rBet v 1wt, and rBet v 1 mut. IgE-binding capacity of purified rMal $\mathrm{d} 1 \mathrm{wt}$ and rMal d 1 mut (a, b, left), and rBet $\mathrm{v}$ 1wt and rBet v 1mut (a, b, right) were tested with 9 serum samples derived from apple-allergic patients (lanes 1-9). A serum pool from non-allergic healthy donors (lane 10) and buffer (lane 11) were run in parallel as controls. Bound IgE was detected with radiolabelled ${ }^{125}$ I-rabbit antihuman IgE antibodies (IBL, Hamburg, Germany).

Fig. 4. IgE ELISA of rMal d 1wt, rMal d 1 mut, rBet v 1wt, and rBet v 1mut. Sera from 14 apple-allergic patients (No. 10-23) were tested with rMal d 1wt, rBet v 1wt, and the mutants thereof. IgE reactivity to the mutants is expressed as decrease when compared to IgE binding to the respective wildtypes $(100 \%)$. Actual OD values are given below the figure.
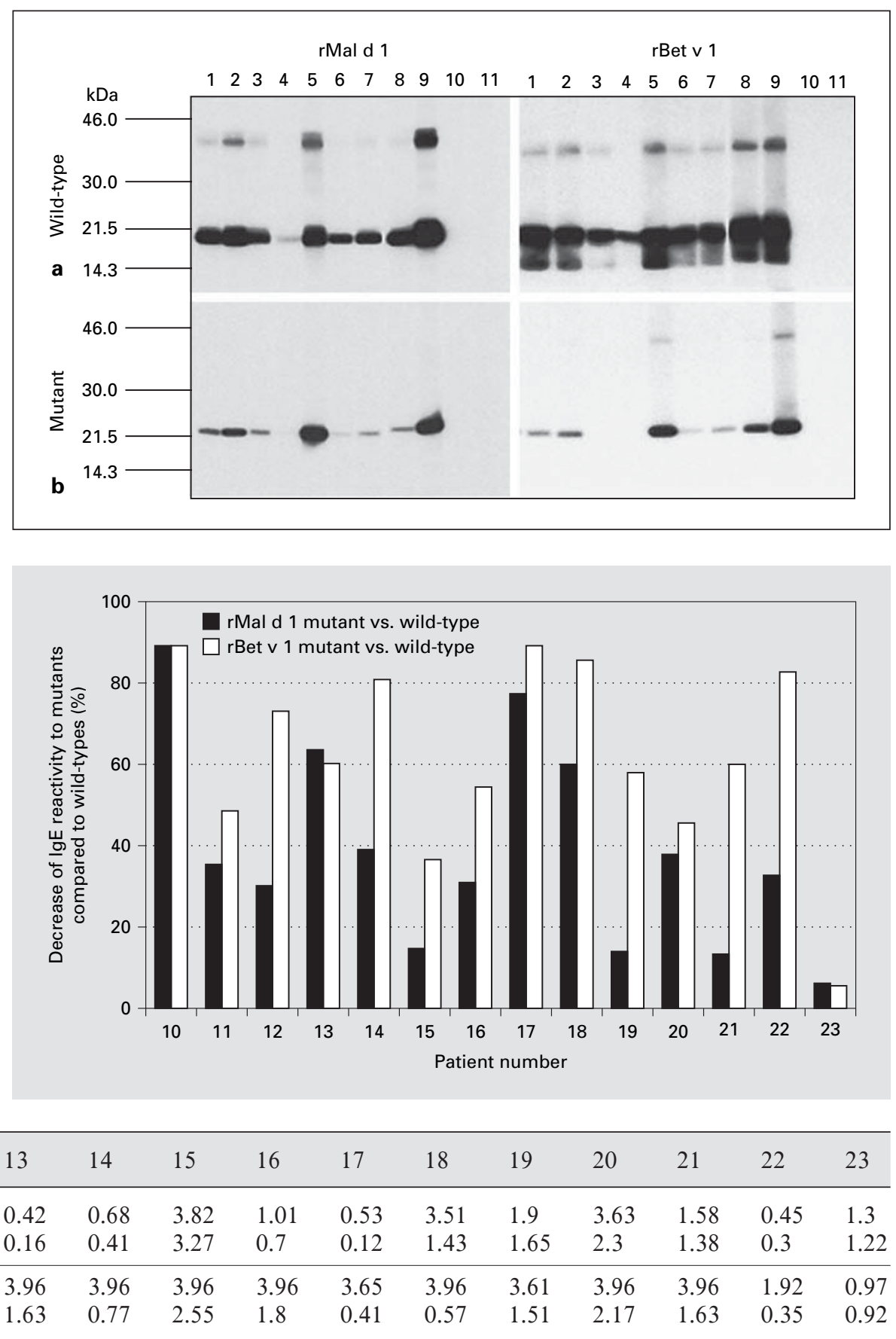

\section{Influence of Amino Acid Substitutions on Antibody \\ Binding}

To evaluate the antibody-binding properties of the engineered proteins compared to the corresponding wildtypes, we performed immunoblotting experiments.

Sera from 9 apple-allergic patients (fig. 3, lanes 1-9) were tested in immunoblots for $\mathrm{IgE}$ recognition of $\mathrm{rMal}$ d 1 wt and rBet v 1 wt (fig. 3a), and rMal d 1 mut and rBet v 1 mut (fig. 3b), respectively. The main band recognized by the IgE antibodies from patient sera was detected at $17 \mathrm{kDa}$ (monomeric form of rMal d 1wt, rMal d 1mut, rBet v 1wt, and rBet v 1mut). For some samples, a fainter band at approximately $34 \mathrm{kDa}$ was also evident representing the dimeric forms of rMal d 1wt, rBet v $1 \mathrm{wt}$, and 
Table 1. Proliferative responses of PBMC of allergic patients (No. 26-30) to purified rMal d 1wt and rMal d 1 mut

\begin{tabular}{|c|c|c|c|c|c|c|c|}
\hline & \multirow{2}{*}{$\begin{array}{l}\text { Medium } \\
\mathrm{cpm} \times 1,000\end{array}$} & \multicolumn{3}{|c|}{ rMal d 1wt } & \multicolumn{3}{|c|}{ rMal d 1mut } \\
\hline & & $25 \mu \mathrm{g} / \mathrm{ml}$ & $12.5 \mu \mathrm{g} / \mathrm{ml}$ & $6.3 \mu \mathrm{g} / \mathrm{ml}$ & $25 \mu \mathrm{g} / \mathrm{ml}$ & $12.5 \mu \mathrm{g} / \mathrm{ml}$ & $6.3 \mu \mathrm{g} / \mathrm{ml}$ \\
\hline 26 & 0.64 & 21.63 & 9.21 & 2.49 & 17.00 & 4.96 & 5.39 \\
\hline 27 & 31.19 & 84.82 & 74.68 & 62.02 & 56.53 & 53.04 & 51.49 \\
\hline 28 & 12.47 & 43.32 & 40.54 & 37.53 & 24.15 & 16.34 & 11.41 \\
\hline 29 & 2.16 & 8.20 & 7.09 & 6.67 & 5.80 & 7.04 & 7.08 \\
\hline 30 & 3.28 & 58.48 & 64.40 & 61.72 & 43.01 & 49.68 & 38.31 \\
\hline
\end{tabular}

rBet $\mathrm{v} 1$ mut as it has previously been shown for rBet $\mathrm{v} 1$ and rApi 1 (fig. 3a, lanes 2, 5, 9 for rMal d 1wt, lanes 2, $5,8,9$ for rBet $\mathrm{v} 1 \mathrm{wt}$ and lanes 5, 9 for rBet $\mathrm{v} 1$ mut [34$36])$. IgE reactivity to $\mathrm{rMal} \mathrm{d} 1 \mathrm{wt}$ was less strong compared to the IgE reactivity to rBet v 1 wt. In 7 out of 9 sera, IgE reactivity to $\mathrm{rMal} \mathrm{d} 1$ mut and $\mathrm{rBet} \mathrm{v} 1$ mut was clearly reduced (fig. 3, lanes 1-4, 6-8). For controls, either normal human serum pool or buffer was used and was negative in all experiments (fig. 3a, b, lanes 10-11).

The IgE binding activities of rMal d 1 wt, rMal d 1 mut, rBet $\mathrm{v} 1 \mathrm{wt}$, and rBet $\mathrm{v} 1$ mut were also tested by ELISA using sera from 14 apple-allergic patients. Figure 4 shows the IgE binding of the mutated proteins compared to the wild-types, Mal $\mathrm{d} 1$ as well as Bet v 1 expressed as decrease in $\operatorname{IgE}$ binding to the mutants when compared to $\operatorname{IgE}$ binding to the respective wild types as a reference (100\%). In addition, the actually obtained OD values are given in figure 4. Ten sera displayed a decrease in IgE-binding activity to rMal d 1 mut of $88-30 \%$ when compared to rMal d 1wt (fig. 4, serum No. 10-14, 16-18, 20, 22). Three sera showed $13 \%$ reduction in $\mathrm{IgE}$ binding to rMal d 1 mut (fig. 4, serum No. 15, 19, 21) and one sample displayed equal IgE reactivity to all four proteins (fig. 4, serum No. 23). The same set of patients' sera displayed reduced IgE reactivity to Bet $v 1$ mut in the range of $89-35 \%$, with only one exception (see above).

\section{Titration SPT}

Two apple-allergic patients were evaluated for their skin test reactivity using purified rMal d $1 \mathrm{wt}$ and $\mathrm{rMal}$ d 1 mut $(0.02,0.2,2,20$, and $100 \mu \mathrm{g} / \mathrm{ml}$, fig. 5; patients No. 24 and 25), respectively. Both patients reacted to rMal d 1wt and rMal d 1mut in a dose-dependent manner. Patient No. 24 showed a wheal area upon exposure to $2-100 \mu \mathrm{g} / \mathrm{ml}$ of rMal d 1 mut that was $52-82 \%$ smaller than the wheal induced by rMal d 1 wt. In patient No. 25 , the wheal areas induced by rMal d 1mut were $51-77 \%$ smaller than those induced by rMal d 1wt.

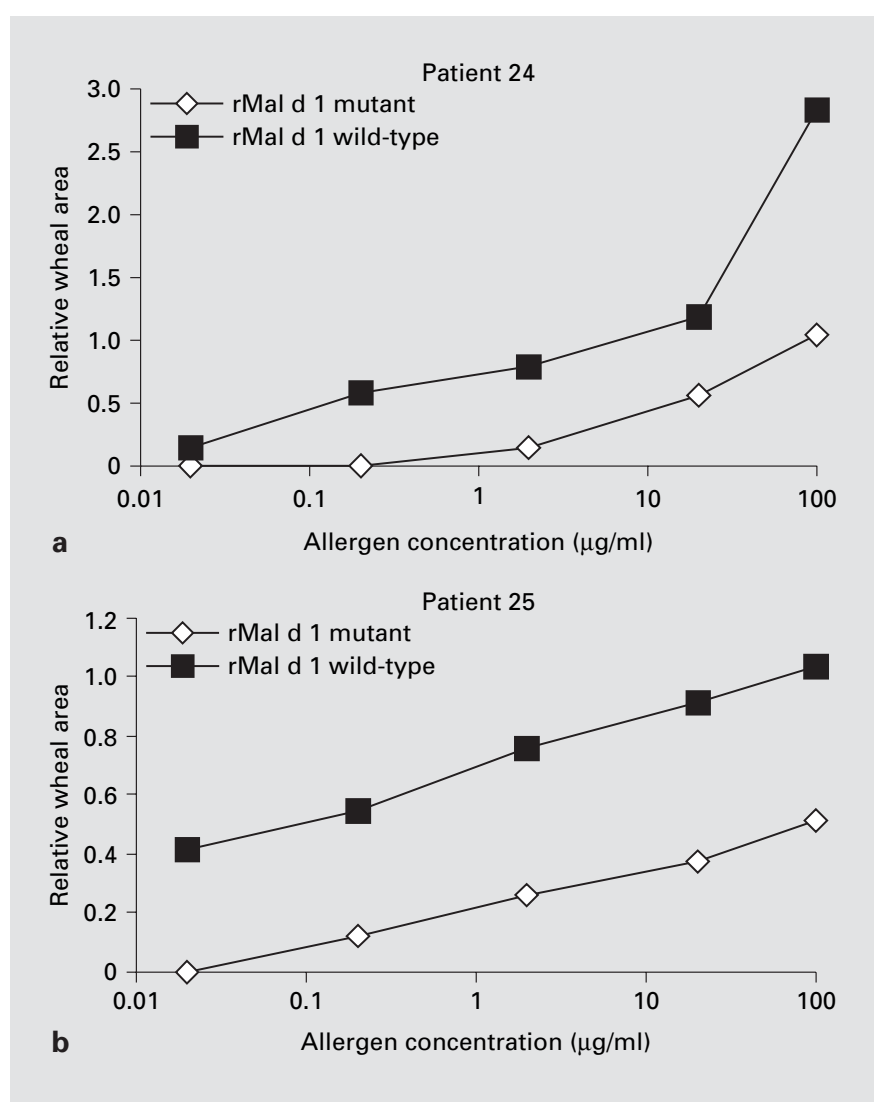

Fig. 5. SPT of purified rMal d 1 wt and rMal d 1 mut. SPT activity was tested in serial dilutions $(\mu \mathrm{g} / \mathrm{ml})$ in 2 patients (patients No. 24 , 25 ). The wheal areas were determined after $15 \mathrm{~min}$ by copying the reaction with adhesive tape onto a record sheet, which was then analyzed by computer scanning $\left(\mathrm{mm}^{2}\right)$ and values are presented as relative wheal areas in relation to the reaction obtained by histamine dihydrochloride. a Patient No. 24. b Patient No. 25.

\section{T Cell Proliferation to rMal d 1wt and rMal d 1mut Proteins}

Proliferative responses to different concentrations of rMal d 1wt and rMal d 1mut were assessed in PBMCs of 5 apple-allergic individuals (table 1; patients No. 26-30). 
Both proteins induced comparable $\mathrm{T}$ cell proliferations upon addition of the recombinant proteins.

\section{Discussion}

In this study we could demonstrate that the amino acid positions involved in the formation of IgE-binding epitopes previously shown for Bet v 1 [19] are also important for Mal d 1, the major apple allergen.

Mal d 1 consists of a number of isoforms [37] but, in contrast to Bet v 1 isoforms [38], no significant differences in IgE-binding activity for individual naturally occurring Mal d 1 isoforms could be identified [37]. We have chosen Mal d 1.0108 (EMBL Genbank Database accession No. AJ417551), identical to Mal d 1a at the amino acid level (clone GD26 from Golden Delicious, EMBL Genbank Database accession No. AF126402 [37]) as the wild type (Mal d 1wt), and obtained a Mal d 1 mutant (Mal d 1mut) by site-directed mutagenesis. Both sequences were expressed in E. coli and purified to homogeneity by chromatographic procedures. The integrity of the primary structure of the purified proteins was evaluated by mass spectrometry. Our CD spectroscopy experiments showed that the overall secondary structure contents of Mal d 1wt and Mal d 1mut were very similar. Thus, it seems that the amino acid substitutions did not cause major disturbances in the protein fold and structural characteristics.

Interestingly, the introduced mutations changed the thermostability of Mal d 1. In contrast to rMal d 1wt, rMal d 1 mut did not completely refold after heating to $95^{\circ} \mathrm{C}$. Based on statistical examination of structural and sequence parameters influencing thermostability of proteins preferred and avoided residues in thermophilic proteins can be identified [39]. In this context the Asn57 and Cys112 exchange as well as the Thr10Pro and Ile30Val exchange contribute to an overall decrease in the thermostability of rMal d 1mut [40, 41].

The IgE binding capacity of rMal d $1 \mathrm{wt}$, rMal d 1 mut, rBet v 1wt, and rBet v 1mut was tested in immunoblots using sera from allergic patients. In addition to the major band migrating at $17 \mathrm{kDa}$, an additional, fainter band around $34 \mathrm{kDa}$ was detected by specific IgE by the more sensitive IgE immunoblot. Bet v 1 and homologous proteins tend to form dimers as has been shown for Bet $\mathrm{v} 1$ and Api g 1 previously [34-36]. Six out of 9 sera showed decreased binding to rMal d 1 mut when compared to rMal d $1 \mathrm{wt}$. This was also the case when testing rBet $\mathrm{v} 1 \mathrm{wt}$ and rBet $\mathrm{v} 1 \mathrm{mut}$.
Performing IgE ELISA, the majority of another set of patients' sera (10/14) tested showed a decrease by $88-$ $30 \%$ in IgE binding to rMal d 1 mut compared to rMal d 1wt. This effect was reduced in three serum samples (decrease by 13\%) and was not observed in one sample that displayed also no difference when testing IgE binding to rBet v 1wt and rBet v 1mut. Again in the case of rBet $\mathrm{v} 1 \mathrm{wt}$, the decrease in IgE binding was more pronounced compared to rMol d 1wt.

It seems that mutagenesis of the selected five amino acid positions in the Mal d 1 sequence did not affect the major epitopes recognized by IgE antibodies among a subset of patients' sera tested. Sequence comparison between Mal d 1 isoform a (synonymous to Mal d 1.01) and isoform b (synonymous to Mal d 1.02, EMBL Genbank Database accession No. L42952 [37, 42]) shows that besides the positions selected for mutagenesis they differ in 12 amino acid positions $(9,16,40,47,70,78,82,98,107$, 125, 126, and 152). Positions 47, 70, and 98 are identical in the Mal d 1 isoforms and Bet $\mathrm{v} 1 \mathrm{a}$. Thus the remaining residues represent unique exchanges associated with the Mal d $1 \mathrm{~b}$ group of isoforms and could lead to the induction of IgE antibodies directed to additional epitopes not influenced by the exchanges present in the mutants. Nevertheless, these antibodies might still cross-react with Bet v 1a and Mal d 1a isoforms, as our experiments showed. If apple-allergic patients are preferentially exposed to Mal $\mathrm{d} 1 \mathrm{~b}$ isoforms, it would explain why for a small sub-set of our patients the introduced mutations did not significantly affect the recognition of Mal d 1. Recently, it has been shown by quadrupole time-of-flight mass spectrometry that natural Mal d 1 contains mostly Mal d 1b-like isoforms [43]. Furthermore, cDNAs coding for Mal d 1b (synonymous to Mal d 1.02) are also the most abundant Mal d 1 sequences detected in apples [42].

The in vitro data revealed that $\mathrm{IgE}$ binding to $\mathrm{rMal}$ d 1 mut was decreased by $88-13 \%$ compared to IgE binding to rMal d $1 \mathrm{wt}$ depending on the serum samples used. However, in in vivo tests the hypoallergenic nature of rMal d 1mut was demonstrated by skin prick testing of 2 apple-allergic patients. Compared to rMal d 1wt, rMal d 1 mut showed a strongly reduced (50-82\%) capacity to induce typical skin reactions. These results are in good agreement with other in vivo tests performed with $\mathrm{rMal}$ d 1wt and rMal d 1mut by Bolhaar et al. [44].

In contrast, both recombinant allergens, rMal d $1 \mathrm{wt}$ and rMal d 1 mut were able to activate and induce proliferation of allergen-specific $\mathrm{T}$ cells from apple-allergic patients. 
So far, relevant IgE epitopes have been determined from the cherry homologue, Pru av 1 [45] another Bet v 1 homologous food allergen. Similar to Bet v 1, the socalled p-loop was identified as a crucial B-cell epitope in Pru av 1 [46]. A second epitope has recently been described by Wiche et al. [47], who showed that amino acid position 28 was crucial for this epitope which is located in the helix 2 area and is clinically relevant to pollen fruit cross-reactivity. Despite different amino acid positions, these findings are in agreement with our point mutation of Ile30Val in Mal d 1mut since they are all part of the same secondary structure motif.

Although these reports clearly point to hot spots critical for IgE binding, no linear epitopes on Bet $\mathrm{v} 1$ have been identified so far. Thus, the conserved overall 3D structure of the protein seems to be a prerequisite for IgE binding. If the structure is disrupted, a dramatic reduction of either IgE binding or IgE-dependent reactions can be observed. This was shown by the single amino acid exchange Ser 112 of Pru av 1 by Neudecker et al. [46] that resulted in an unfolded protein [46]. The recombinant trimer of Bet $\mathrm{v} 1$ displaying a reduced IgE binding capacity and in vivo allergenic activity is another example of the concept of unfolded or not properly folded proteins [48]. It remains to be established on a whole range of proteins whether the concept of unfolded/misfolded denatured proteins as postulated by Crameri [49] or the theory of point-mutated proteins targeting the major IgE epitopes is the method of choice for developing hypoallergenic vaccines for SIT for the benefit of the vast majority of allergic patients.

In conclusion, the results presented here showed that it is possible to decrease the IgE-binding affinity of epitopes by single amino acid substitutions at crucial positions. Recombinant Mal d 1mut carrying 5-amino-acid substitutions showed decreased allergenicity in vitro and in vivo and conserved antigenicity in terms of $\mathrm{T}$ cell recognition when testing a number of apple-allergic patients. Our experiments also showed that these 5-amino-acid substitutions affected the overall $\mathrm{IgE}$ recognition of Mal d 1 . In cases where birch pollen immunotherapy based on Bet $\mathrm{v} 1$ desensitization fails to ameliorate the associated Mal d 1induced food-allergic symptoms, the concept of mutated hypoallergenic food allergens seems to offer new possibilities. Furthermore, there is a need in the food allergic population to eat the offending food again but without concomitant symptoms, since the allergic consumers want to extend their daily diet and to intake fresh fruit together with vitamins. This has been investigated by a consumer survey across Europe [50]. Thus, the Mal d 1 mut described here can serve as template for engineering a hypoallergenic vaccine for apple-allergic patients. Injection of such engineered hypoallergens for immunotherapy could modulate the allergic immune response at the level of the Thelper cell, but with a substantially decreased risk of anaphylactic (IgE-mediated) side effects during treatment.

\section{Acknowledgements}

This work was supported by grant P16456-B05 (to F.F.), SFB F18-07 (to B.B.) from the Fonds zur Förderung der Wissenschaftlichen Forschung, Vienna, Austria, and Project QLK1-CT-200001394, SAFE supported by the European Commission, Framework 5 and from the Austrian Ministery for Education, Science and Culture.

\section{References}

1 Eriksson NE, Formgren H, Svenonius E: Food hypersensitivity in patients with pollen allergy. Allergy 1982;37:437-443.

2 Wuthrich B, Stager J, Johansson SG: Celery allergy associated with birch and mugwort pollinosis. Allergy 1990;45:566-571.

3 van Ree R, Aalberse R: Pollen-vegetable food crossreactivity: serological and clinical relevance of crossreactive IgE. J Clin Immunoassay $1993 ; 16: 124-130$

-4 Ebner C, Hirschwehr R, Bauer L, Breiteneder H, Valenta R, Ebner H, Kraft D, Scheiner O: Identification of allergens in fruits and vegetables: IgE cross- reactivities with the important birch pollen allergens Bet $\mathrm{v} 1$ and Bet $\mathrm{v} 2$ (birch profilin). J Allergy Clin Immunol 1995;95: 962-969.

-5 Breiteneder H, Hoffmann-Sommergruber K, O'Riordain G, Susani M, Ahorn H, Ebner C,
Kraft D, Scheiner O: Molecular characterization of Api g 1, the major allergen of celery (Apium graveolens), and its immunological and structural relationships to a group of 17 $\mathrm{kDa}$ tree pollen allergens. Eur J Biochem 1995; 233:484-489.

6 Hoffmann-Sommergruber K, O'Riordain G, Ahorn H, Ebner C, Laimer-Da-Camara-Machado $\mathrm{M}$, Puhringer $\mathrm{H}$, Scheiner O, Breiteneder H: Molecular characterization of Dau c 1, the Bet $\mathrm{v} 1$ homologous protein from carrot and its cross-reactivity with Bet v 1 and Api g 1. Clin Exp Allergy 1999;29:840-847.

-7 Vanek-Krebitz M, Hoffmann-Sommergruber K, Laimer da Camara Machado M, Susani M, Ebner C, Kraft D, Scheiner O, Breiteneder H: Cloning and sequencing of Mal d 1, the major allergen from apple (Malus domestica), and its immunological relationship to Bet $\mathrm{v} 1$, the ma- jor birch pollen allergen. Biochem Biophys Res Commun 1995;214:538-551.

-8 Wensing $\mathrm{M}$, Akkerdaas JH, van Leeuwen WA, Stapel SO, Bruijnzeel-Koomen CA, Aalberse RC, Bast BJ, Knulst AC, van Ree R: IgE to Bet v 1 and profilin: cross-reactivity patterns and clinical relevance. J Allergy Clin Immunol 2002;110:435-442.

-9 Vieths S, Schoning B: Characterization of Mal $\mathrm{d} 1$, the $18-\mathrm{kD}$ major apple allergen, at the molecular level. Monogr Allergy 1996;32:63-72.

10 Fritsch R, Ebner C, Kraft D: Allergenic crossreactivities. Pollens and vegetable foods. Clin Rev Allergy Immunol 1997;15:397-404

11 Tuft L, Blumenstein G: Studies in food allergy. J Allergy 1942;13:574-581.

12 Bjoerksten F, Halmepuro L, Hannuksela M, Lahti A: Extraction and properties of apple allergens. Allergy 1980;35:671-677. 
13 Asero R: Effects of birch pollen SIT on apple allergy: a matter of dosage? Allergy 2004;59: 1269-1271.

-14 Bolhaar ST, Tiemessen MM, Zuidmeer L, van Leeuwen A, Hoffmann-Sommergruber K, Bruijnzeel-Koomen CA, Taams LS, Knol EF, van Hoffen E, van Ree R, Knulst AC: Efficacy of birch-pollen immunotherapy on cross-reactive food allergy confirmed by skin tests and double-blind food challenges. Clin Exp Allergy 2004;34:761-769.

- 15 Hansen KS, Khinchi MS, Skov PS, BindslevJensen C, Poulsen LK, Malling HJ: Food allergy to apple and specific immunotherapy with birch pollen. Mol Nutr Food Res 2004;48: 441-448.

-16 Ebner C, Siemann U, Bohle B, Willheim M, Wiedermann U, Schenk S, Klotz F, Ebner H, Kraft D, Scheiner O: Immunological changes during specific immunotherapy of grass pollen allergy: reduced lymphoproliferative responses to allergen and shift from $\mathrm{TH} 2$ to $\mathrm{TH} 1$ in T-cell clones specific for Phl p 1, a major grass pollen allergen. Clin Exp Allergy 1997;27:1007-1015.

-17 Blaser K, Akdis CA: Interleukin-10, T regulatory cells and specific allergy treatment. Clin Exp Allergy 2004;34:328-331.

-18 Savolainen J, Laaksonen K, Rantio-Lehtimaki A, Terho EO: Increased expression of allergeninduced in vitro interleukin-10 and interleukin-18 mRNA in peripheral blood mononuclear cells of allergic rhinitis patients after specific immunotherapy. Clin Exp Allergy 2004;34:413-419.

-19 Ferreira F, Ebner C, Kramer B, Casari G, Briza P, Kungl AJ, Grimm R, Jahn-Schmid B, Breiteneder H, Kraft D, Breitenbach M, Rheinberger HJ, Scheiner O: Modulation of $\mathrm{IgE}$ reactivity of allergens by site-directed mutagenesis: potential use of hypoallergenic variants for immunotherapy. FASEB J 1998;12: 231-242.

-20 Wallner M, Gruber P, Radauer C, Maderegger B, Susani M, Hoffmann-Sommergruber K, Ferreira F: Lab scale and medium scale production of recombinant allergens in Escherichia coli. Methods 2004;32:219-226.

-21 Hoffmann-Sommergruber K, Susani M, Ferreira F, Jertschin P, Ahorn H, Steiner R, Kraft D, Scheiner O, Breiteneder H: High-level expression and purification of the major birch pollen allergen, Bet v 1. Protein Expr Purif 1997;9:33-39.

-22 Willerroider M, Fuchs H, Ballmer-Weber BK, Focke M, Susani M, Thalhamer J, Ferreira F, Wuthrich B, Scheiner O, Breiteneder H, Hoffmann-Sommergruber K: Cloning and molecular and immunological characterisation of two new food allergens, Cap a 2 and Lyc e 1, profilins from bell pepper (Capsicum annuum) and Tomato (Lycopersicon esculentum). Int Arch Allergy Immunol 2003;131:245-255.

-23 Guex N, Peitsch MC: Swiss-Model and the Swiss-PdbViewer: an environment for comparative protein modeling. Electrophoresis 1997; 18:2714-2723.

-24 Himly M, Jahn-Schmid B, Dedic A, Kelemen P, Wopfner N, Altmann F, van Ree R, Briza P, Richter K, Ebner C, Ferreira F: Art v 1, the major allergen of mugwort pollen, is a modular glycoprotein with a defensin-like and a hydroxyproline-rich domain. FASEB J 2003; 17 106-108.

25 Wopfner N, Willerroider M, Hebenstreit D, van Ree R, Aalbers M, Briza P, Thalhamer J, Ebner C, Richter K, Ferreira F: Molecular and immunological characterization of profilin from mugwort pollen. Biol Chem 2002;383:1779-1789.

26 Dreborg S: Allergen standardisation and skin tests. EAACI position paper. Allergy 1993;48: 49-82.

27 Laemmli UK: Cleavage of structural proteins during the assembly of the head of the bacteriophage T4. Nature 1970;227:680-685.

28 Towbin H, Staehelin T, Gordon J: Electrophoretic transfer of proteins from polyacrylamide gels to nitrocellulse sheets: procedure and some applications. Proc Natl Acad Sci USA 1979;76: 4350-4354.

29 Jarolim E, Rumpold H, Endler AT, Ebner H, Breitenbach M, Scheiner O, Kraft D: IgE and IgG antibodies of patients with allergy to birch pollen as tools to define the allergen profile of Betula verrucosa. Allergy 1989;44:385-395.

30 Dreborg S, Foucard T: Allergy to apple, carrot and potato in children with birch pollen allergy. Allergy 1983;38:167-172.

31 Poulsen LK, Liisberg C, Bindslev-Jensen C, Malling $\mathrm{H}$ : Precise area determination of skin prick tests: validation of a scanning device and software for a personal computer. Clin Exp Allergy 1993;23:61-68

32 Bohle B, Radakovics A, Jahn-Schmid B, Hoffmann-Sommergruber K, Fischer GF, Ebner C: Bet v 1, the major birch pollen allergen, initiates sensitization to Api g 1, the major allergen in celery: evidence at the T cell level. Eur J Immunol 2003;33:3303-3310.

-33 Hirel PH, Schmitter MJ, Dessen P, Fayat G, Blanquet S: Extent of N-terminal methionine excision from Escherichia coli proteins is governed by the side-chain length of the penultimate amino acid. Proc Natl Acad Sci USA 1989;86:8247-8251.

34 Friedl-Hajek R, Radauer C, O'Riordain G, Hoffmann-Sommergruber K, Leberl K, Scheiner $\mathrm{O}$, Breiteneder $\mathrm{H}$ : New Bet v 1 isoforms including a naturally occurring truncated form of the protein derived from Austrian birch pollen. Mol Immunol 1999;36:639-645.

>35 Hoffmann-Sommergruber K, Demoly P, Crameri R, Breiteneder H, Ebner C, Laimer-DaCamara-Machado M, Blaser $\mathrm{K}$, Ismail C, Scheiner O, Bousquet $\mathrm{J}$, Menz G: IgE reactivity to Api g 1, a major celery allergen, in a Central European population is based on primary sensitization by Bet v 1. J Allergy Clin Immunol 1999; 104:478-484.

-36 Hoffmann-Sommergruber K, Ferris R, Pec M, Radauer C, O'Riordain G, Laimer Da Camara Machado M, Scheiner O, Breiteneder H: Characterization of Api g 1.0201, a new member of the Api g 1 family of celery allergens. Int Arch Allergy Immunol 2000;122:115-123.

37 Son DY, Scheurer S, Hoffmann A, Haustein D, Vieths S: Pollen-related food allergy: cloning and immunological analysis of isoforms and mutants of Mal d 1, the major apple allergen, and Bet v 1, the major birch pollen allergen. Eur J Nutr 1999;38:201-215.
38 Ferreira F, Hirtenlehner K, Briza P, Breiteneder H, Scheiner O, Kraft D, Breitenbach M, Ebner C: Isoforms of atopic allergens with reduced allergenicity but conserved $\mathrm{T}$ cell antigenicity: possible use for specific immunotherapy. Int Arch Allergy Immunol 1997;113: 125-127.

39 Kumar S, Tsai CJ, Nussinov R: Factors enhancing protein thermostability. Protein Eng 2000; 13:179-191

-40 Schindler T, Mayr LM, Landt O, Hahn U, Schmid FX: The role of a trans-proline in the folding mechanism of ribonuclease T1. Eur J Biochem 1996;241:516-524.

41 Eyles SJ, Gierasch LM: Multiple roles of prolyl residues in structure and folding. $\mathrm{J}$ Mol Biol 2000;301:737-747.

42 Puehringer HM, Zinoecker I, Marzban G, Katinger H, Laimer M: MdAP, a novel protein in apple, is associated with the major allergen Mal d 1. Gene 2003;321:173-183.

43 Helsper JP, Gilissen LJ, van Ree R, America $\mathrm{AH}$, Cordewener JH, Bosch D: Quadrupole time-of-flight mass spectrometry: a method to study the actual expression of allergen isoforms identified by PCR cloning. J. Allergy Clin Immunol 2002;110:131-138.

44 Bolhaar STHP, Zuidmeer L, Ma Y, Ferreira F, Bruijnzeel-Koomen CAFM, Hoffmann-Sommergruber K, vanRee R, Knulst AC: A mutant of the major apple allergen, Mad d 1, demonstrating hypoallergenicity in the target organ by double-blind placebo-controlled food challenge. Clin Exp Allergy 2005; doi: 1111/ j.1365.2222.2005.02390.x.

45 Neudecker P, Schweimer K, Nerkamp J, Scheurer S, Vieths S, Sticht H, Rosch P: Allergic cross-reactivity made visible: solution structure of the major cherry allergen Pru av 1. J Biol Chem 2001;276:22756-22763.

46 Neudecker P, Lehmann K, Nerkamp J, Haase T, Wangorsch A, Fotisch K, Hoffmann S, Rosch P, Vieths S, Scheurer S: Mutational epitope analysis of Pru av 1 and Api g 1, the major allergens of cherry (Prunus avium) and celery (Apium graveolens): correlating $\mathrm{IgE}$ reactivity with three-dimensional structure. Biochem J 2003;376:97-107.

$\checkmark 47$ Wiche R, Gubesch M, Konig H, Fotisch K, Hoffmann A, Wangorsch A, Scheurer S, Vieths S: Molecular basis of pollen-related food allergy: identification of a second cross-reactive IgE epitope on Pru av 1, the major cherry (Prunus avium) allergen. Biochem J 2005;385:319-327.

48 Vrtala S, Hirtenlehner K, Susani M, Akdis M, Kussebi F, Akdis CA, Blaser K, Hufnagl P, Binder BR, Politou A, Pastore A, Vangelista L, Sperr WR, Semper H, Valent P, Ebner C, Kraft D, Valenta R: Genetic engineering of a hypoallergenic trimer of the major birch pollen allergen Bet v 1. FASEB J 2001; 15:2045-2047.

49 Crameri R: Correlating IgE reactivity with three-dimensional structure. Biochem J 2003; 376:e1-e2.

50 Miles S, Bolhaar ST, Gonzalez-Mancebo E, Hafner C, Hoffmann-Sommergruber K, Fernandez-Rivas M, Knulst AC: Attitudes towards low-allergen food in food allergic consumers. Nutr Food Sci 2005;35:220-228. 